\title{
ЗНАЧЕНИЕ ОСНОВНЫХ СРЕДСТВ В ДЕЯТЕЛЬНОСТИ ЭКОНОМИЧЕСКИХ СУБЪЕКТОВ
}

\section{(c) 2020 Пайтаева Комета Тахировна}

кандидат экономических наук, доцент кафедры «Учёт, анализ и аудит в цифровой экономике», Институт экономики и финансов Чеченский государственный университет, Россия, Грозный

E-mail: kometa_1972@mail.ru

В данной статье рассмотрены некоторые вопросы учета, аудита и анализа использования основных средств предприятия. Подчеркнута роль основных средств в формировании конечных результатов деятельности. Охарактеризованы обновленные формы статистической отчетности о наличии и движении основных фондов (средств) и других нефинансовых активов.

Ключевые слова: основные средства, аудиторская проверка, система бухгалтерского учета, аудиторское заключение, анализ эффективности использования основных средств.

Каждый хозяйствующий субъект представляет собой определенную систему, функционирующую и развивающуюся в конкретной бизнес-среде, которая характеризует многообразие и структуру систем бухгалтерского учета, аудита, финансового анализа и обладает при этом выраженной спецификой вида деятельности и организационно-технического уровня.

При этом уровень технического развития и технологичность производства играют первостепенную роль в росте объемов производства и расширении производства. Уровень технического развития определяется наличием техники, которая в денежном выражении определяется, как обеспеченность основными фондами (основными средствами).

В настоящее время жесткие законы рыночной экономики диктуют субъектам хозяйствования необходимость и важность проведения всестороннего и своевременного анализа для определения результатов хозяйственной деятельности и диагностики финансового состояния предприятия. Прибыльность предприятия во многом определяется уровнем использования ресурсов производства. Оценка обеспеченности и эффективности использования основных средств - это важное направление комплексного экономического анализа, позволяющего оценить уровень внедрения достижений научно-технического прогресса, эффективность техники и технологии.

Продолжительность срока полезного использования определяется в зависимости от того, насколько полезно использование конкретного объекта, или это может определяться объемом продукции, которую можно производить на данном оборудовании.

Формами годовой (периодической) отчетности, где приводятся сведения о наличии и составе основных средств являются форма № 1 «Бухгалтерский баланс» и форма № 5 «Приложение к бухгалтерскому балансу», раздел «Амортизируемое имущество».

Эффективность работы предприятия во многом зависит от эффективности использования ресурсов производства.

В современных условиях масштабного внедрения достижений научно-технического прогресса, которое выражается в совершенствовании техники и технологий, основные средства являются объектом пристального внимания всех экономических служб организации.

При этом заметно возрастает роль бухгалтерского учета основных средств, от правильности ведения которого зависит себестоимость произведенной продукции, оказанных услуг, выполненных работ, а, следовательно, и величина прибыли. Учет должен давать объективную информацию о состоянии и движении основных средств, их технического состояния и эффективного использования. Учет основных средств ведется с использованием различных процедур и различных документов первичного и синтетического учета. Процедурными вопросами по учету основных средств являются: оценка, система и методы амортизации, порядок приема и выбытия, основы их списания. Все эти вопросы отражаются в учетной политике организации. 
Аудиторская проверка служит важным инструментом для решения вопросов сохранности и эффективности использования основных средств. Аудит использования основных средств проводится по определенному плану в соответствии с разработанной в аудиторской организации программой. Программа должна включать все основные этапы и процедуры аудиторской проверки, основные методы, используемые аудиторами.

Основная цель аудита - это проверка финансовой отчетности предприятия, которая является основной формой, где отражаются финансовые результаты, уровень финансового состояния, система показателей, характеризующих рыночные позиции организации.

Соблюдение нормативных документов по учету основных средств, принятой учетной политики позволяет осуществлять точный и оперативный контроль над их наличием и использованием. По результатам данной проверки аудитор дает оценку состоянию учета и контроля основных средств. Наиболее действенным инструментом по контролю сохранности основных средств служит и инвентаризация. Аудитор должен проверить наличие на предприятии инвентаризационной комиссии, наличие плана инвентаризаций, правильность отражения результатов инвентаризации в регистрах бухгалтерского учета.

В случаях отсутствия объективной системы инвентаризационного контроля аудитор может потребовать проведения инвентаризации в процессе проведения аудиторской проверки.

Для углубленной проверки наличия и сохранности основных средств аудитор может потребовать инвентарного списка всех основных средств, к которому должны быть приложены документы, отражающие операции по переоценке основных средств, а также информация об арендованных средствах.

Известно, что основные средства представлены обширным списком, и объем информации составляет значительную долю в бухгалтерском учете, поэтому аудитору необходимо проверить большой перечень документов по учету поступления, движению и выбытию основных средств.

Аудиторские организации широко используют процедуры встречной проверки, т.е. проверяются документы как у предприятия, так и у поставщиков основных средств, для чего используются методика выборочной проверки по отдельным объектам основных средств.

При проверке операций по учету движения основных средств необходимо определить основные пути их поступления, направления выбытия, перемещение по соответствующим подразделениям.

Для фиксации операций поступления и выбытия основных средств должна быть создана специальная комиссия, которая документально подтверждает акт принятия или списания соответствующего объекта.

Наличие такой комиссии и ее полномочия также являются объектами аудиторской проверки. При этом необходимо проверить правильность ведения записей в инвентарных карточках.

В практике аудиторской проверки операций, связанных с основными средствами, выявляются типичные для этих операций ошибки.

K типичным ошибкам ведения учета основных средств относятся следующие:

- несмотря на соответствующие указания в учетной политике, для аналитического учета не используются инвентарные каточки (№ OC-6), а учет ведется по инвентарным спискам, в которых зачастую не регистрируются большинство операций по основным средствам;

- при определении материальной ответственности ограничиваются собственными основными средствами;

- часто встречаются случаи несоответствия данных аналитического и синтетического учета данным Главной книги;

- для уменьшения объемов учетной работы и арифметических расчетов процедура амортизационных начислений проводится не ежемесячно, а ежеквартально;

- неправомерно используется метод ускоренной амортизации и начисление амортизации по объектам с истекшим нормативным сроком эксплуатации.

Структура аудиторского заключения представляется тремя частями. В первой части отражается информация, дающая общие сведения об аудируемой организации. Во второй (аналитической части) находит свое отражение информация о результатах проведенной проверки, состояние системы учета и контроля предприятия, о соответствии отчетности действующим нормативным документам. В аналитической части указываются также выявленные нарушения в системе учета и отчетности. Третья часть аудиторского заключения в принципе и есть мнение 
аудитора или аудиторской организации о достоверности финансовой отчетности организации.

Аудиторское заключение представляется аудиторской организацией, индивидуальным аудитором только аудируемому лицу либо лицу, заключившему договор оказания аудиторских услуг [1]. Аудиторское заключение представляется руководству аудируемой организации в полном тексте, т.е. все разделы внешним пользователям - в части первого и третьего разделов. Аудиторское заключение имеет важное значение для собственников предприятия, позволяет вести контроль за уровнем финансового состояния, определять направления дивидендной политики, осуществлять рациональную инвестиционную политику, дать оценку эффективности работы управленческого персонала.

Основным видом внешнего контроля выступает ведомственная ревизия и контроль налоговых органов. Налоговые органы в части основных средств проверяют правильность начисления сумм амортизации. Это объясняется тем, что амортизация влияет на себестоимость продукции, что в свою очередь определяет уровень прибыли. Следовательно, контроль за системой амортизации для налоговых органов это контроль за точностью определения суммы прибыли. От точности определения суммы прибыли зависят суммы налоговых отчислений в бюджеты разных уровней.

Финансовый результат деятельности предприятия напрямую зависит от технического потенциала, основным элементом которого являются основные производственные фонды.

В зависимости от целей составления и состава пользователей финансовая отчетность разделяется на внешнюю и внутреннюю.

Правовая регламентация играет немаловажную роль в бухгалтерском учете любого экономического субъекта, так как достоверный и единообразный подход к объективному отражению фактов хозяйственный жизни напрямую влияет на финансово-хозяйственную деятельность экономического субъекта.

Основные средства формируют главную составляющую материально-технической базы предприятия и играют определяющую роль в осуществлении профильных направлений его деятельности [3]. Рациональное использование основных средств предопределяет их значимость для процесса производства. Проблемы безопасности ведения бизнеса и развития эко- номики в нашей стране занимают особое место на современном этапе развития. Являясь неотъемлемой частью предпринимательской среды, риски выступают факторами поиска новых приемов и методов их обнаружения в процессе разработки, принятия и внедрения управленческих решений.

Точный и своевременный учет поступления, движения и использования основных фондов позволяет предприятиям точно определять потребность в них, выявлять излишек или недостаток основных средств, контролировать рациональное их использование. С развитием рыночных отношений в учете основных средств произошли существенные изменения [3].

Приказом от 15.07.20 г. № 384 «Об утверждении формы федерального статистического наблюдения для организации федерального статистического наблюдения за наличием и движением основных фондов (средств) и других нефинансовых активов» Федеральная служба государственной статистики утвердила новую редакцию трех годовых форм статистической отчетности, которые начнут применяться с отчетности за 2020 год. В связи с этим действовавшие с 04.07.19 г. бланки упраздняются.

С 30.12.2020 установлено, что формы федерального статистического наблюдения, предоставляются респондентами в форме электронного документа, подписанного электронной подписью, если иное не установлено федеральными законами. При этом в отношении респондентов - СМП указанное правило применяется с 1 января 2022 г. [1]

Перечень утвержденных новых форм выглядит следующим образом:

- форма № 11 «Сведения о наличии и движении основных фондов (средств) и других нефинансовых активов»;

- форма № 11 (сделка) «Сведения о сделках с основными фондами на вторичном рынке и сдаче их в аренду;

- форма № 11 (краткая) «Сведения о наличии и движении основных фондов (средств) некоммерческих организаций».

Первую форму представляют все юридические лица, в независимости от видов экономической деятельности, ведомственной принадлежности, форм собственности и организационно-правовых форм. Исключение составляют некоммерческие организации и малые предприятия. Сам состав формы не изме- 
нился. Как и прежде, бланк состоит из титульного листа и пяти разделов.

Однако сократилось количество строк в таблице раздела II «Наличие и движение основных фондов по видам экономической деятельности». Срок представления -1 апреля.

В указаниях по заполнению данной формы появились таблицы соответствия:

- кодов ОКОФ видовой структуры фондов (для заполнения раздела I);

- буквенного и цифрового кода видов экономической деятельности по ОКВЭД 2.

Отмечается, что если в отчетном периоде у хозяйствующего субъекта не было основных фондов, то в статорган следует направить пустой отчет по форме № 11.

Форма №11 (сделка) не изменилась. Ее представляют средние и крупные предприятия, осуществляющие все виды экономической деятельности, имеющие основные фонды на счетах по учету основных средств и доходных вложений в материальные ценности. Если в отчетном периоде у хозяйствующего субъекта не было основных фондов, то в статорган ничего не следует направлять.

Изменился на один день срок сдачи отчета.
Вместо 30 июня данную форму можно представить 1 июля.

Форму №11 (краткую) представляют экономические субъекты независимо от вида экономической деятельности, ведомственной принадлежности, формы собственности, являющиеся некоммерческими организациями, частные учреждения, общественные учреждения, благотворительные и иные фонды, объединения юридических лиц (ассоциации и союзы). Срок представления -1 апреля.

Важнейшей характеристикой внешней среды функционирования экономических субъектов в современном мире является ее непредсказуемость [2]. Эффективное использование всех имеющихся ресурсов имеет важное значение в условиях обострения конкурентной борьбы. Поэтому следует непрерывно вести поиск резервов и путей повышения эффективности производства. Только на основе качественно проведенных аналитических исследований возможно определить резервы роста производства за счет оптимизации использования средств производства и применять их в рамках реализации экономической стратегии развития предприятия.

\section{Библиографический список}

1. Федеральный закон «Об аудиторской деятельности» от 30.12.2008 г. № 307-ФЗ (редакция от 29.12.2020 г.). Режим доступа: http://www.consultant.ru/ document/cons_doc_LAW.

2. Пайтаева К. Т. Финансовые результаты деятельности предприятия: сущность, классификация, анализ // Экономические науки. - № 181.-2019.- С. 141-145.

3. Цацулин А. Н. Экономический анализ.- СПб.: Питер, 2014.-704 с. 